
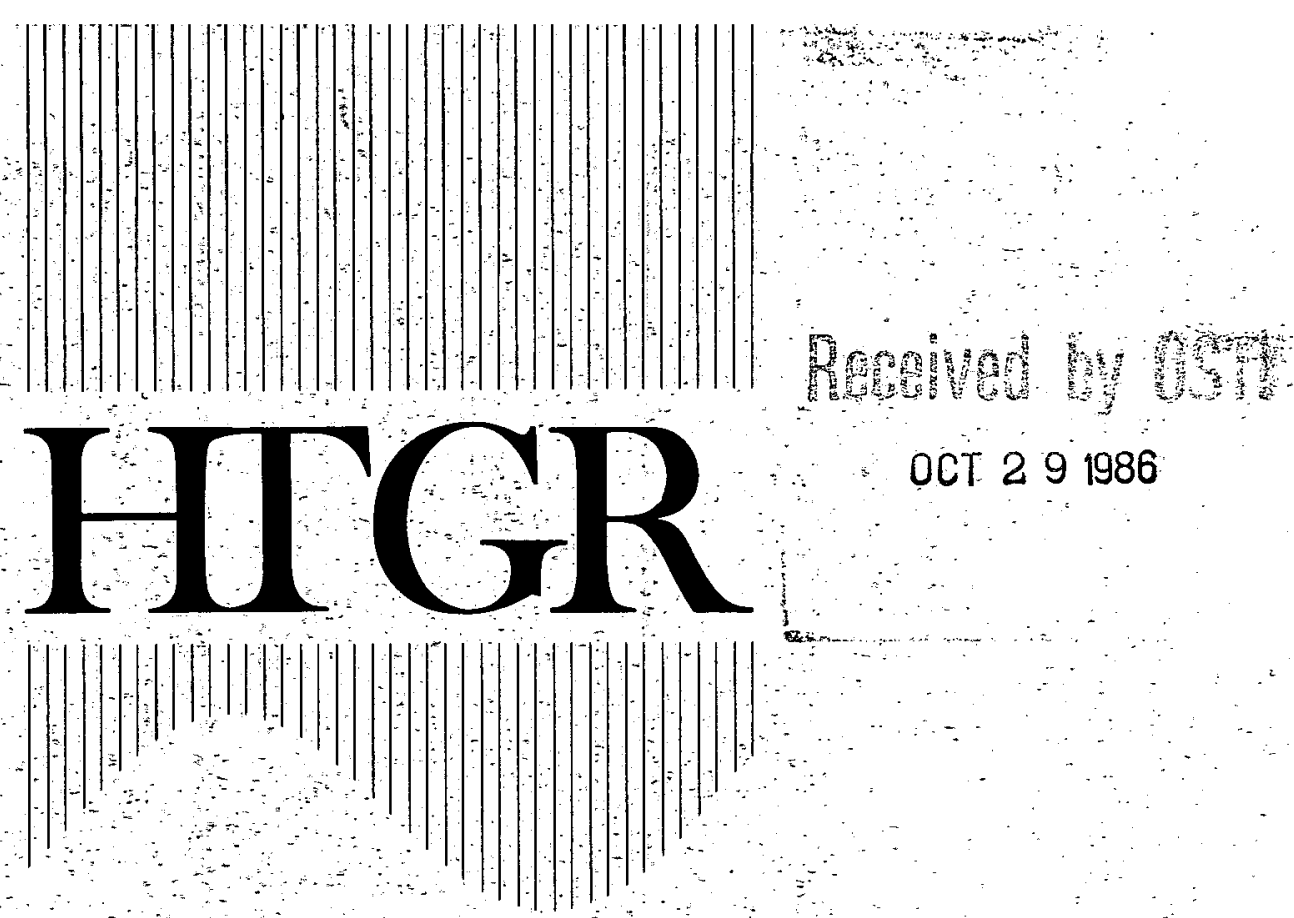

\title{
GRAPHITE CRITERIA PEER REVIEW
}

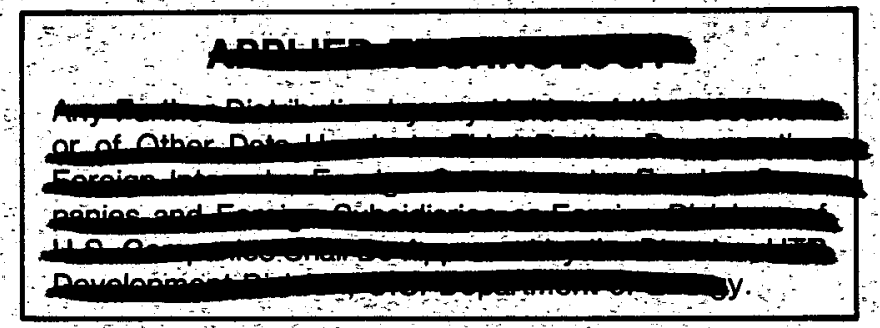

\section{AUTHORS/CONTRACTORS}

DOWOHWOML

GA TECHNOLOGIES INC.

60ven

This cocument is

PUBLICLY :RELEASABLE

PeR MeMo DruId A STENMAN, General ATOMics Classirication GENACER $1 / 22 \%$ I Helen Allen
ISSUED BY GA TECHNOLOGIES INC. FOR THE DEPARTMENT OF ENERGY CONTRACT DE-AC03-84SF 11962 


\section{DISCLAIMER}

This report was prepared as an account of work sponsored by an agency of the United States Government. Neither the United States Government nor any agency Thereof, nor any of their employees, makes any warranty, express or implied, or assumes any legal liability or responsibility for the accuracy, completeness, or usefulness of any information, apparatus, product, or process disclosed, or represents that its use would not infringe privately owned rights. Reference herein to any specific commercial product, process, or service by trade name, trademark, manufacturer, or otherwise does not necessarily constitute or imply its endorsement, recommendation, or favoring by the United States Government or any agency thereof. The views and opinions of authors expressed herein do not necessarily state or reflect those of the United States Government or any agency thereof. 


\section{DISCLAIMER}

Portions of this document may be illegible in electronic image products. Images are produced from the best available original document. 
HTGR-86-104

909028/10

NOTICE

This report contains information of a preliminary nature and installation. It is subject to revision or correction and therefore

does not represent a final report. It is passed to the recipient in

confidence and should not be abstracted or further disclosed

swithout the approval of the originating installation of USDOE

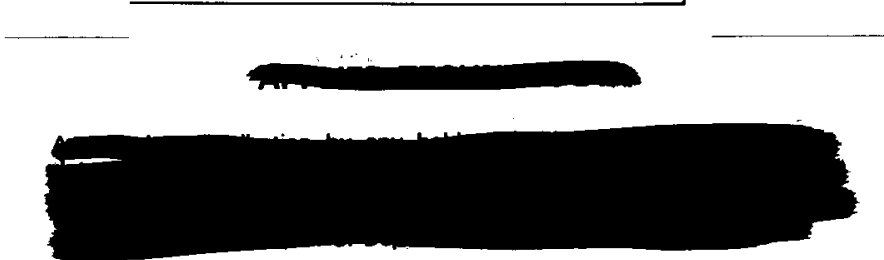

GRAPHITE CRITERIA PEER REVIEW

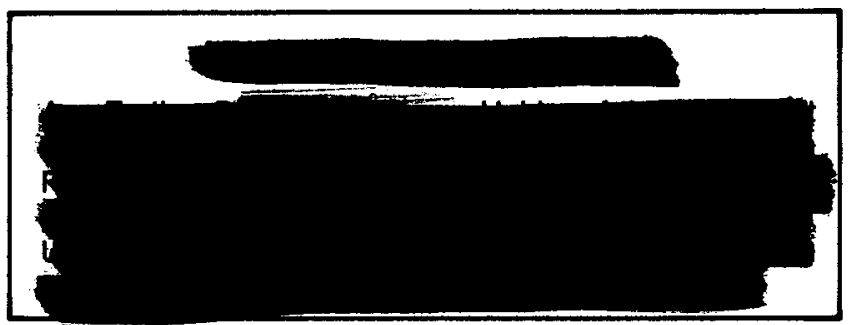

This document is

PUBLICLY RELEASABLE

PeR Memo. DAUId A. STe inMan,

General Atomics Classification

Orfficer i/23/Ol Helew Allen

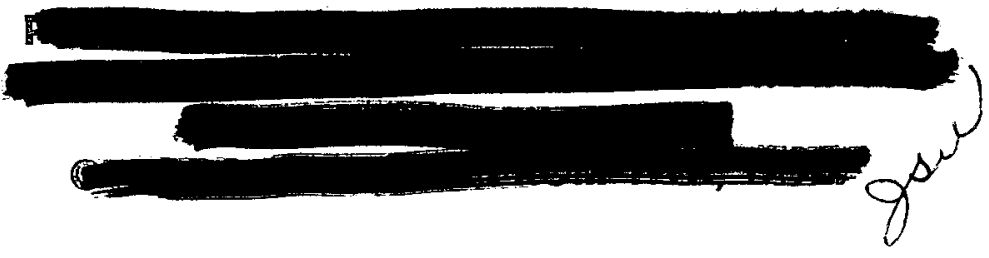

Issued By:

GA Technologies Inc.

P.O. Box 85608

San Diego, California 92138-5608

DOE Contract No. DE-AC03-84SF11962

GA Project 6300 
This report was prepared as an account of work sponsored by the United States Government. Neither the United States nor the United States Department of Energy, nor any of their employees, makes any warranty, express or implied, or assumes any legal liability or responsibility for the accuracy, completeness, or usefulness of any information, apparatus, product, or process disclosed, or represents that its use would not infringe privately owned rights. Reference herein to any specific commercial product, process, or service by trade name, mark, manufacturer, or otherwise, does not necessarily constitute or imply its endorsement, recommendation, or favoring by the United States Government or any agency thereof. The views and opinions of authors expressed herein do not necessarily state or reflect those of the United States Government or any agency thereof. 


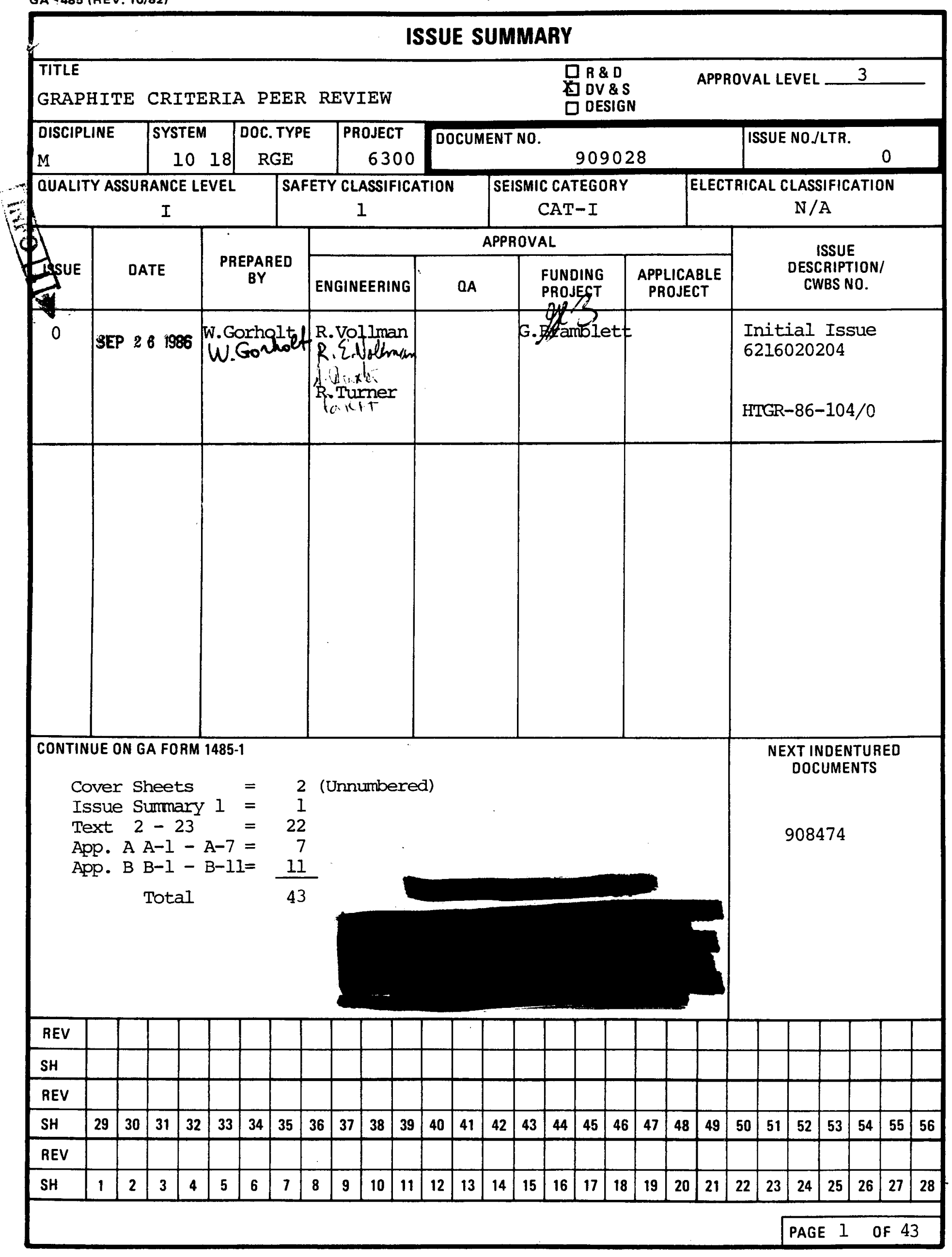




\section{CONTENTS}

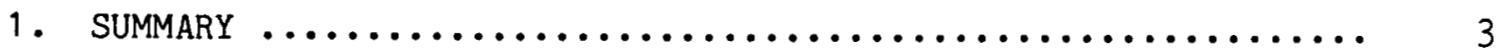

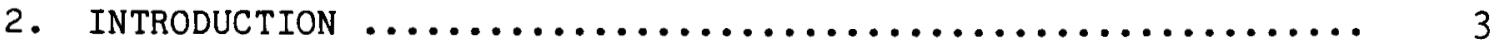

3. REVIEW COMMENTS ........................... 5

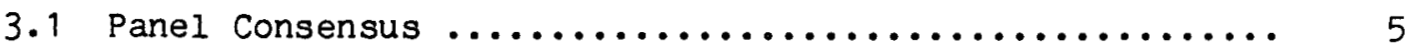

3.2 Detailed Comments by Individual Panel Members $\ldots \ldots \ldots \ldots . .7$

3.2 .1 Comments by C. A. Cornell ................. 7

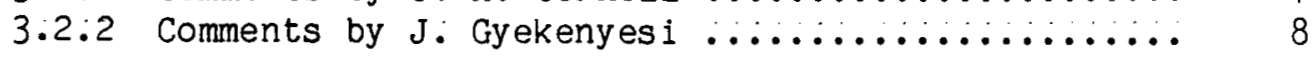

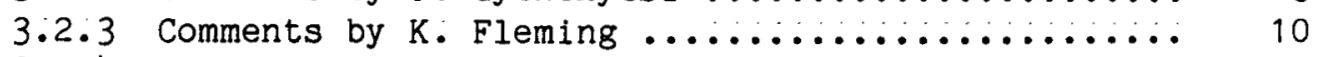

$3: 2.4$ Comments by $R$. Meyer .......................... 15

3.2 .5 Comments by $P$ : Riccardella ................... 16

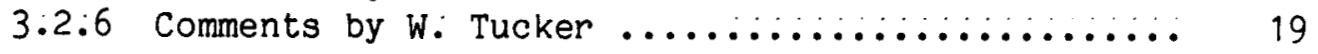

4. RESOLUTION OF REVIEW COMMENTS $\ldots \ldots \ldots \ldots \ldots \ldots \ldots \ldots \ldots \ldots \ldots . \ldots \ldots$

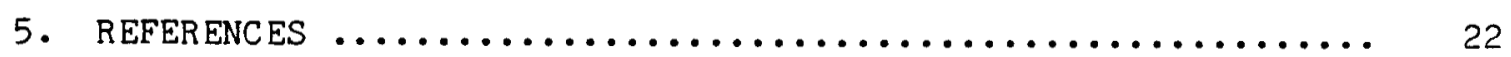

APPENDIX A: MINUTES FROM NOVEMBER MEETING $\ldots \ldots \ldots \ldots \ldots \ldots \ldots \ldots$ A-1

APPENDIX B: MINUTES FROM FEBRUARY MEETING $\ldots \ldots \ldots \ldots \ldots \ldots \ldots \ldots$. 


\section{SUMMARY}

This report documents a review of the stress criteria proposed for the graphite components of the modular high temperature gas-cooled reactor (MHTGR) core. The review was conducted by a panel of six independent consultants, chosen for their expertise over a range of relevant disciplines.

The review took place during the fiscal year (FY) 1986 and included three meetings in November, February, and September, respectively. of these the last one was particularly important, because at that meeting three documents central to the graphite criteria issue was reviewed. The first document is the "Core Graphite Conceptual Design Criteria" (Ref. 5) which contains the first quantified stress criteria developed with the probabilistically based approach. The second document is the "Graphite Technology Development Plan" (Ref. 4) which presents the technology needed for completing the criterla development work. Both these documents were prepared under the Department of Energy (DOE) funded program. The third document, on the other hand, was commissioned by the Gas Cooled Reactor Associates (GCRA) as a study of alternative approaches (Ref. 6).

The review of these three documents generated many comments, both from the panel as a whole and from each individual panelist. In general, the panel was supportive of the approach taken in the DOE program, but identified a number of areas, particularly in the statistical treatment, where corrections, improvements, and further development are necessary. The study of alternative approaches was recognized for focusing attention on the important issue of volume effect, that is, to what extent the strength of graphite is affected by the volume of material under stress.

Some of the most significant comments have already been acted on and are affecting the plans for the continued criteria development work in FY-87. The full resolution of the comments, however, requires more time and will be completed at a later date.

\section{INTRODUCTION}

This report documents the results of an independent review of the stress criteria for the replaceable graphite components of the Modular High Temperature Gas-Cooled Reactor (MHTGR) core. The review was performed by a panel of six consultants selected to provide a range of relevant expertise. The six consultants, their specialties, and their affiliations are:

Dr. C. Allin Cornell, acting as an individual consultant. Expert in structural safety and structural criteria development. Active as a consultant on seismic issues of nuclear plant licensing. Professor at Stanford University, previously at MIT. 
Mr. Karl Fleming, of Pickard, Lowe and Garrick Inc. Expert on probabilistic risk assessment (PRA) and active as a consultant on PRA aspects of light-water reactor (LWR) licensing.

Dr. John Gyekenyesi, acting as an individual consultant. Expert on probabilistic design methods for ceramic components, specifically for advanced gas turbine engines. Affiliated with NASA-Lewis.

Dr. Robert Meyer, of The Aerospace Corporation, acting as an individual consultant. Expert on graphite material development for components used in severe aerospace applications. Previously with Brookhaven National Lab and active in development of nuclear graphites.

Dr. Peter Riccadella, of Structural Integrity Associates. Expert on fracture mechanics, specializing in consulting services relating to fracture mechanics aspects of LWR pressure vessel licensing.

Dr. William Tucker, of General Electric Co. Member of staff of GE's corporate research center. Expert on general probability theory and application to engineering problems.

The need for a peer review of the graphite criteria was expressed by the Department of Energy (DOE) in the summer of 1985, after GA Technologies Inc. (GA) had proposed to develop such criteria on a probabilistic basis. The review program started with an introductory meeting at GA on November 19 and 20, 1985. At that meeting, R. Ng from DOE stated the objectives of the review. These were to assess whether the proposed approach was sound in principle and licensable and whether the necessary supporting technology could be developed at a reasonable cost and schedule.

At the introductory meeting, engineers from $G A$ and Oak Ridge National Laboratory (ORNL) presented the panel members with background information and explained the proposed approach which is to use PRA methods to establish criteria which will then be expressed as conventional stress to strength limits for use by the designers. The background information included design descriptions, alternatives considered, and graphite material characteristics. The role of ORNL is to be responsible for the graphite technology program which, in light of the third objective, is within the scope of the peer review.

The minutes from the introductory meeting were issued by the panel's secretary, Graham Jones from Gas Cooled Reactor Associates (GCRA). The complete minutes (Ref. 1) include the presentation material from the meeting as attachments. An abbreviated version of the minutes, excluding the attachments and the transmittal latter, but otherwise identical to Ref. 1 , is contained in Appendix A. As can be seen in Appendix A, the panel expressed their support in general for the proposed approach, identified several weak areas, and asked for more specific information on the intended implementation of the approach. 
At the end of the introductory meeting, a report (Ref. 2) which describes the methods and techniques used in the PRA analysis, was distributed to the panel members. Comments generated by Ref. 2 and by the other information provided at the introductory meeting resulted in a second meeting held at GA on February 4, 1986. The minutes from this second meeting were issued by Sam Hosegood from GCRA, acting for Graham Jones. The abbreviated minutes are contained in Appendix B, which is identical to the full minutes (Ref. 3 ) except that the transmittal letter is omitted. As can be seen from Appendix $B$, the comments from the second meeting were more detailed and in greater depth than those from the first meeting. One of the comments was a request for the committee to review the Graphite Technology Development Plan which was then under preparation.

The Graphite Technology Development Plan (Ref. 4) was issued in July. Copies were soon thereafter mailed to the panelists. At about the same time a report entitled "Core Graphite Conceptual Design Criteria" was completed in draft form and was also mailed to the panel members. This report (Ref. 5) contains the first actual stress criteria developed with the approach reviewed at the first two meetings. A third meeting was set for September 4 and 5 to review the graphite plan and the criteria report. The comments resulting from this meeting and GA's disposition of these comments are discussed in sections 2 and 3, respectively.

In parallel with GA's DOE funded work of issuing Refs. 4 and 5 , GCRA had separately commissioned Structural Integrity Associates (SIA). of San Jose, where one of the six panelists, P. Riccardella is an associate, to evaluate other potential approaches to graphite criteria. This work is documented in Ref. 6 which also was mailed to the panelists and discussed at the September meeting.

\section{REVIEW COMMENTS}

This section contains the comments resulting from the peer review of the graphite plan (Ref. 4), the criteria report (Ref. 5), and SAI's study of alternative approaches (Ref. 6). The section is divided into Subsection 3.1 which gives the panel consensus and Subsection 3.2 which gives detailed comments from each panel member.

\subsection{PaneI Consensus}

In this subsection the panel comments from the review meeting September 4 and 5, are extracted from the meeting minutes (Ref. 7). Together, the set of comments expresses the panel consensus. The grouping of the comments corresponds to the three objectives of the peer review:

1. Is the approach sound in principle?

2. Is the approach licensable? 
3. Can the supporting technology program be developed at a reasonable cost and schedule?

Soundness of Overall Graphite Criteria Approach

1. Significant progress is evident since the last review.

2. The panel were still concerned over how uncertainties were being combined.

3. The panel requested that GA prepare a listing of all subjective and random variables with a statement on each as to how it is being handled.

4. There was concern over the mesh size in the finite element analysis, given the very peaked nature of the stress distribution.

5. The panel questioned whether the conclusions that the use of the SIA calculation method resulted in very little difference in the stress level was valid for low stressed blocks or for blocks without local peaks.

6. GA needed to show how temporal and spatial stochastic variability had been accounted for.

7. There was still concern that the probabilistic/engineering interface was not satisfactory.

Licensability of the Approach

1. No new comments. (At the first meeting, see Appendix A, the panel commented that the approach is licensable if thoughtfully "packaged" and presented.)

2. It was suggested that $G A$ make a comparison between the failure probabilities for the MHTGR fuel elements and those for the LWR fuel cladding.

Technology Plan

1. Overall the document was judged to be sound and a good top-down approach.

2. There is a need for a carefully planned test for volume effects and it was proposed that the panel review the test plan at an early stage.

3. The overall technology development plan should be reevaluated after the above tests and after items 2 through 6 under the soundness of approach above have been concluded. 
4. Prioritization needs to be improved.

5. An enhanced understanding is needed at the microstructural level of the material property variabilities and failure mechanisms.

6. The plan showed too much assumption that the ASME Code approach for metals was valid for graphite. For instance fatigue testing was included for completeness even though it was not thought to be important.

\subsection{Detailed Comments by Individual Panel Members}

\subsubsection{Comments by C. A. Cornell}

As the work progresses, I believe the soundness of the general top-down, PRA-based approach to the project and to criteria development in particular is making itself strongly evident. It is seen in these reports in several forms. Perhaps the two strongest are (1) the systematic development of the tasks outlined in the Graphite Technology Development Plan and (2) the understanding gained about major contributors to randomness and uncertainty. The latter characteristic could, however, in my opinion have been used more directly and formally in the formulation of the scope and details (e.g., relative testing effort) of the Technology Development Plan.

The report entitled Core Graphite Conceptual Design Criteria represents a good beginning, but the stochastic model remains too crude for its ultimate purpose. Two items are representative: (1) the simplified spatial correlation treatment of physical properties and applied stress and (2) the simple treatment of the time-varying aspects (e.g., time(s) of occurrence of the shutdown-induced stresses vis-a-vis the life of the fuel element, the gap size space-time treatment, presumably, if treated similarly, seismic events and spatial temporal variations of stresses within events, etc.). Improvement of the first of these simplifications (less than perfect spatial correlation in thermal expansion and creep coefficient) is likely to give important benefits in the reduction of the stress variability (COV) and hence in the increase in the allowable stress ratio.

Secondly, the treatment of model and parameter uncertainty (although not yet clearly recorded in this overview report) also apparently needs enhancement in several respects. As mentioned above, a good treatment of such uncertainty will give benefits in test planning and elsewhere. This report (particularly as revised) is very clearly organized and written.

With respect to the Technology Development $\mathrm{Plan}$ report, I find it also well organized (if a little overwhelming in its rigid format). In general, it appears well thought out and thorough. Consistent with my comments above, I would, however, like to see greater emphasis on verification and/or parameter estimation of the temporal and spatial 
assumptions in the stochastic model (e.g., the spatial correlation function of the creep coefficient). ApparentIy NDT density evaluations may go a long way in assessing spatial statistical varlability. I am left wondering about how strongly some of the several assumptions of insensitivity to irradiation will be confirmed.

Finally with respect to the SIA report, I find that the independent approach has forced some new, hard thinking by the "Weibull advocates." It raises the question of how many alternative models should be formally considered (in this and other areas where alternative, "nonrefutable" models might be hypothesized). It shows that there may be reason to expect at very large element sizes quite different (better) strengths than the current data set might suggest (although one need not go to the Rose-Tucker model to conclude this). The report re-emphasizes the importance of obtaining quickly a few strength tests from specimens of at least ligament-level volumes (i.e., about 4 in. ${ }^{3}$ ). It also makes it necessary to reconfirm the stated $G A$ conclusion that the size-reduction effect is no more than $10 \%$ (because of the peaked stress field) even with the simple uni-model Weibull model. The SIA report seems to contradict this. The reason(s) for this discrepancy need to be established. Who's right?

My comments are intended to be constructive. In total I applaud the work and remain convinced that it is technically sound, that it can be licensed, and that the technology program is balanced and adequate.

\subsubsection{Comment by J. Gyekenyesi}

1. Design Criteria for HTGR Fuel Elements and Other Replaceable Graphite Components (Ref. 6)

When working with brittle materials, it is generally more rigorous and advantageous to work with established failure probabilities and probabilistic design procedures than with deterministic, fixed stress/strength ratios. The random nature of material strength, probably the driver in establishing design, can be accounted for by weibull or other statistics, while uncertainties in loading, stress analysis, mechanical and physical properties, etc. can be lumped into an appropriate safety factor. There is rigorous mathematics available in the literature to convert failure probabilities into safety factors for these who must think in terms of traditional design allowable stress/strength ratios. To judge the merits of different fracture models from the crude approximations in this report is clearly impossible. There are just too many unanswered questions on input data, that is whether we have a bimodal weibull material or not, whether density gradients contributed to the resulting differences, how good was the stress solution, required material properties, and so on. The proposed Buch, Tucker-Rose microstructural model has been severely criticized previously as not representative of the actual graphite failure process. 
Most experimentalists have claimed, at least for isotropic, relatively fine-grained polycrystalline graphite, that failure occurs because of pre-existing, natural flaws and not from newly developing, coalescing cracks. For these types of failures, linear elastic fracture mechanics (LEFM) based on Griffith concepts provides the best and most rational explanation of material behavior. Because of multidimensional stress states, the use of mixed-mode fracture criteria is essential. Batdorf's theory is the only approach that retains the advantages of weakest link statistics while incorporating essential elements of Griffith fracture mechanics. With appropriate and careful material characterization and required 3-D finite element stress analysis, a rigorous probabilistic design can be completed that includes the advantages of using this model when compared to the "old way" of using excessive safety factors. With the availability of supercomputers, accurate finite element analysis programs and special purpose reliability codes like SCARE, there is no need to search for unnecessary, inaccurate, and unreliable approximation. The required design goal failure probabilities for individual components in the reactor can be established from appropriate PRA procedures and there is no need then for different stress/ strength allowable ratios for individual reactor components, operating at different conditions.

2. Core Graphite conceptual Design Criteria

The philosophical comments I made in connection with SIA's report (Ref. 6) also apply to this section. Using PRA to establish numerical values of stress/strength ratios, linking functional damage to investment $r$ isks and safety goals seem to be appropriate, but I fail to see why this same approach could not be used to establish desired fallure rates. It seems to me when structural mechanics and the engineering analysis procedures are turning increasingly probabilistic, why in such high-technology industry as nuclear reactors, the same trends cannot be sustained. Rigorous statistical material characterization, with adequate fractography, together with modern computers and appropriate software can result in highly efficient, even if not minimum weight, graphite reactor cores and even core support structures.

The artificial drive to use deterministic stress/strength ratio allowables, even in the ASME code, is entirely unnecessary and criteria in specified component failure probabilities would be much more meaningful. Time-dependent damage, such as static or dynamic fatigue, could be accounted for by specifying allowable changes in the individual component failure rates. The crack-stopping features of current fuel elements with all the drilled holes can also be accounted for probabilistically by permitting higher failure rates as needed. Multiaxial weakening can be calculated from several 
probabilistic fracture theories, such as Weibull, Batdorf, and others. Undoubtedly, Weibull statistics with mechanistically based fracture theories provide the most accurate description of brittle, porous material behavior under tensile loading. If needed, subcritical crack growth can also be included in the modeling along with environmental effects. As pointed out by ORNL and T. Yahr, LEFM consistently described graphite behavior with great accuracy.

3. Graphite Technology Development Plan (Ref. 4)

Summarizing required future graphite technology plan needed for the design of the MHTGR considering all possible failure modes in a "top-down" manner is obviously very helpful from both the engineering and funding viewpoints. However, there are too many unanswered issues in this document, which from my own experience with ceramics, do not apply to brittle materials. Among these I can list

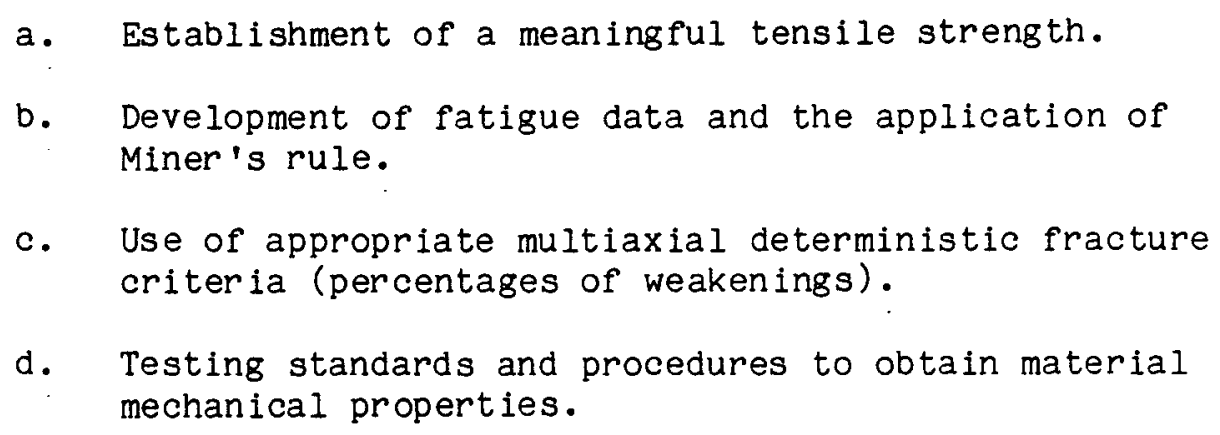

I am convinced if graphite exhibits weakest link material properties, then most of the technology activities planned in this document can be explained through rational, mechanistic engineering principles and not base them on only phenomenological behavior in the laboratory. In addition, the extra care needed for brittle materials, such as post mortem fractography, avoiding potential alignment problems, surface sensitivity, environmental behavior, specimen sizes, etc. all must be carefully included in the planning.

It is my impression that this document is heavily influenced by past experience with graphite, with extensive influence from traditional metal structure design philosophy. How much of this traditional thinking can be used here is not clear to me, but in truly brittle polycrystalline materials, it would not lead to safe and reliable components. And an " $m$ " value of 7 typically would be of a truly brittle material.

\subsubsection{Comments by K. Fleming}

My comments on the three reports are documented in the following. As a preface to these comments, I would like to point out that I have 
restricted most of these to areas that relate to my own areas of expertise, particularly the areas of probability, statistics, probabilistic risk assessment technology, and reactor safety. This resulted in my providing comments only on the first two documents. I assume, with confidence, that my distinguished colleagues on the review panel with expertise in materials sclence, ceramics, and graphite will cover their respective areas so that the entire panel will provide a complete review.

1. Core Graphite conceptual Design Criteria (Ref. 5)

a. (General Comment). This document and the others, to varying degrees, have a problem with probabilistic terminology that stems from the use of both interpretations of the concept of "probability." Probability is being used, on the one hand, as meaning the relative frequency of occurrence of some truly random variable. On the other hand, it is used to connote a measure of the degree of belief or state-of-knowledge about the value of some uncertain quantity, which, in most cases, is not a random variable. Because of this, it is difficult to determine what is realiy meant by statements such as that on the top of page 5, "uncertainties in the applied stresses and in the strength of the material..." Stresses can be both variable and unknown, whereas, strength is simply unknown. Failure to sort out these different meanings is very important, because each has a different impact in the way the computations are performed. One suggestion is to present relative frequency type probabilities as "type R Probability," and the subjective probabilities as "Type S Probability."

b. (General Comment). Another terminology problem related to the above stems from the use of the terms, "mean, median, mode, etc.," i.e., parameters of probability distributions. When such terms are used, it should be made clear as to which distribution is being referred to. For example, in the middle of page 20 , the "mean value of the strength" is used to compute the ratio that is the center piece of the proposed stress criteria. Is this the mean of the frequency distribution of test data on tensile strength, or mean of a distribution that includes uncertainty, or what? Similarly, what is meant on page 20 by the statement, "Similar mean values?"

c. (Section 2.7). Isn't there a safety function or criterion to prevent graphite burning? Also, isn't it the function of the fuel particle coatings to retain fission product coatings? I believe the ability of graphite to retain fission products that escape the fuel particle coatings is rather limited. 
d. (Section 3.1.1). The stress-to-strength ratio is specified as the ratio of stress calculated in terms of mean values of various properties to a mean strength. The result of taking this ratio can be regarded as a mean stress-to-strength ratio, if all the variables, upon which the strength and stress are a function of, are also independent. Otherwise, this ratio of means may not be tied directiy to any known parameter or percentile of the distribution of stress-to-strength ratios.

What is meant on page 20 as a "statistically valid" data base?

How are uncertainties in the stress calculation model, temporal variations in operating environments, and random behavior of plant operating histories being addressed in estimation of failure probability?

In view of the fact that there is not a one-to-one correspondence between stress-to-strength ratio and failure probability (i.e., one could have different sets of distributions of strength and stress, each giving rise to a different failure probability, but fortuitously having the same ratio), shouldn't the criteria on page 22 be accompanied by a criteria for an acceptable failure probability?

e. (Section 4.1). Another quantified basis for judging the acceptability of failure probability is to estimate the failure probability associated with some existing LWR components designed to deterministic ASME type codes. Examples would be: core support structure response to seismic loads, primary coolant pipe response to seismic and loss of coolant accident (LOCA) pipe whip loads, and structural response to design basis earthquake loads. After all, the current deterministic criteria utilize implicit probabilistic arguments. If you help the NRC to "calibrate" their scales of acceptable probabilities to past decisions they have already made deterministically, the job of selling the probabilistic criteria could be made easier.

f. (Section 4.2). As noted in comment $d$ above, limits in mean stress to mean strength does not, in itself, ensure that any limits or failure probability are being met. It depends on the details of the underlying distributions.

g. (Section 4.3). On page 27, the definition of unavailability is incorrect. You multiply the downtime by the failure rate, not the failure probability, to approximate the unavailability. 
Plant goals cannot be allocated to systems, subsystems, and components without fixing the functional and intersystem dependencies in the plant. The risk posed by a given plant design may not be directly related to the reliability of any system, depending on how the systems are connected together. Therefore, to allocate system or subsystem reliability, it is also necessary to allocate system dependencies.

h. (Section 4.4). The equations for $P_{f}$ are valid only if $S$ and $\mathrm{L}$ are independent. I believe there are some dependencies, i.e., $S$ and $L$ both depend on spatial dimensions of the graphite material.

On page 29, what is meant by "median stress uncertainty?" What is meant by "median probability of damage?" In both cases, the distributions corresponding to these medians are not defined.

i. (Section 4.5). The term "uncertainty" like "probability" is being used to describe random variables and state-ofknowledge imperfections. Again, how one manipulates the distribution is influenced by which type is being referred to.

On page 30 , it is not known what is meant by the term "random" (perhaps "independence" is what is meant). Also, which things are assumed to be uncorrelated? Monte Carlo simulation is not capable of "estimating uncertainty," but only simulating this by randomly selecting values from an assumed probability distribution that is "estimated" in some other way, i.e., by fitting Weibull distributions to date.

On page 31 , on what basis (or statistical test) was the Gamma distribution determined to be "a good approximation?"

j. (Section 4.6). On the top of page 34, the probability of failure equals $P^{3}$, only if there is one specific sequence of cracks that will produce failure. If the model is any three cracks, or even any three connected cracks, there needs to be more terms added to account for the different possibilities.

k. (Section 4.7). In the second paragraph, the frequency and probability per year are only interchangeable when the annual frequencies are $\ll 1$.

In the last paragraph on page 35, the use of the binomial theorem assumes that the probability of failure of each element is independent of all the other elements' failure 
probabilities. It is not clear that this is the case. As the Fort St. Vrain experience indicates, one would expect the probabilities of failure of elements within a column, for example, to be correlated.

1. (Section 4.9). Even in the assumed absence of uncertainty, absolute reliability is unattainable.

2. Design Criteria for HTGR Fuel Elements and Other Replaceable Graphite Components (Ref. 6)

a. (Pages 2-3). While I agree that fuel element cracking is less significant than LWR or LMFBR clad failure, both the former and the latter are primarily economic (i.e., cleanup) and operational concerns, and not real safety concerns. Probabilistic risk assessment studies on both LWRs and LMFBRs have consistently shown that public health is not threatened unless large scale core melting is postulated.

b. (Pages 2-5). It is noted that the ASME safety factors approach can be regarded as an implicit probabilistic approach. If the uncertainties in the applied stresses and material properties had been larger, it is reasonable to assume that the ASME Code limits would have specified larger safety factors. By retrospectively computing the probability of failure of components designed to the ASME Code, we can put the two approaches into a comparable basis. The probabilistic risk assessment approach need not have the noted disadvantage, as long as designers are provided with limits they can measure or compute with against performance.

c. The fact that SIA calculates different stress levels than $G A$ indicates to me that the overall concept of modeling uncertainty needs to be explicitly taken into account. Perhaps we should use the approach now followed in seismic hazard analysis of admitting different sets of modeling assumptions into the analysis and using expert judgment to assign weights to the various hypotheses admitted.

d. (General). One important source of stress is seismic events. The frequency of seismic events as a function of intensity is known to be highly site specific. This should result in a site-to-site variation in the probability of fallure due to seismic loads. How is this being handled (applies to all documents)? 


\subsubsection{Comments by $\mathrm{R}$. Meyer}

A primary concern is the proper interpretation and utilization for statistical purpose of the physical strength data for the MHTGR type of graphites.

The fracture behavior of graphites is different from either metals or ceramics. Although graphite has small strain values at failure, its modes of approaching failure is different. Experimental fractography studies have shown the generation of numerous disconnected microcracks occurring at low stress levels. Fallure will not occur until a sufficient number of microcracks have coalesced to form a critical crack size. The ease of formation of critical cracks depends on the size and orientation of the grains in the graphite. Each grain is highly anistropic in its ability to resist fracturing or cleavage.

Since the grains are basically randomly oriented, microcracking will first occur in those grains that are oriented with the least strength. Therefore, a random distribution of disconnected microcracks will occur. As further stress is applied, the next level of resistant grains will fracture and the process will be repeated until a sufficient density of cracks is generated to cause failure. The random nature of cracking is modified by the distribution of pores, cracks, and/or voids that surround the grains. If the bonding strength between grains is low, this will also influence the propagation of cracks. Small changes of density are critical since it reflects the degree of porosity and therefore the ease of propagating cracks.

Graphite strain characteristics are also influenced by microcracking since subcritical cracks contribute to dimensional changes of the stressed samples. The ability to microstrain also permits the redistribution of stresses with in the stressed volume, thereby increasing its toughness. This characteristic is important, especially for long-term radiation effects. The redistribution of microcracking with stress has been observed over periods as long as 6 to 8 hours.

This ability of graphites to have multiple cracking or microstrains prior to failure is characteristic of metals. However, the relatively low strain at failure of graphites is similar to ceramics. This means graphites should be considered as unique and the data analyzed accordingly for proper statistical predictions.

In consideration of the above, the following general recommendations are made about the type of information that is desired for proper statistical analysis.

- The volume effect of tensile samples should be evaluated both perpendicular and parallel to the direction of extrusion of the billet or log. 
- The sensitivity to small density changes within and between billets should be determined along with the pore size distribution adjacent to fractured surfaces.

- The microstructure of each type of MHTGR graphite should be determined, especially with respect to the grain and void size distribution and orientation.

Microstructural analyses of each fractured specimen's surface should be made to determine, if possible, the cause of critical crack initiation and propagation.

The implications of these recommendations to the specific proposed test programs will be submitted in another detailed communication.

\subsubsection{Comments by P. Riccardella}

1. Core Graphite Conceptual Design Criteria (Ref. 5)

In general, I believe that $G A$ has made tremendous progress on this effort in the past year. The stress limits presented in Sections 3.1 .1 and 3.1 .2 (for standard fuel elements under normal plant operation) appear to be a practical engineering approach to a complex, multidisciplined design problem. Specifically, the proposed limits on ratios of applied peak stress to mean strength of the material, with adjustments to reflect within block stress distribution (via the "Weibull integral") as well as block-to-block distribution provide a straightforward means of addressing such complexities as volume effect, anisotropy, inhomogeniety, and statistical scatter in strength data, which are characteristic of the graphite fuel element material and necessary elements of any design criteria for this material. Subject to some further checking and verification as described below, I see no problem with the technical soundness of the approach.

One concern regarding the proposed criteria is an apparent lack of a complete understanding of the volume effect on strength of the HTGR core graphite. It appears that definitive tests for this effect, using representative volumes, have not been run. Also, calculations by Structural Integrity Associates (Ref. 6) plus testing of a similar graphite by others (Ref. 8) indicate the Weibull equation, with the parameters currently being used by GA, to substantially underpredict the fracture strength of HTGR fuel blocks under uniform tensile applied loads. It is recognized that the GA method of calculating the Weibull integral over the fuel block, in conjunction with typical fuel element stress distributions, indicates this to not be a significant factor in the PRA. This finding needs to be carefully checked, for a 
wide variety of graphite element types and stress distributions (both in-plane and axial). And even if the GA conclusion holds true on this point, I am still uncomfortable with proposing a strength criteria for fuel elements when we do not understand such a fundamental aspect as the uniaxial tensile strength of a prototypical volume of the material.

A second reservation regarding the technical soundness of the proposed criteria involves the adequacy of the overall PRA. This is not my area of expertise, and I anticipate that several of my colleagues on the peer review committee will be commenting on this topic in detail. Needless to say, my conclusions regarding technical soundness presume a favorable finding by these individuals on the details of the PRA methodology and results.

From the standpoint of licensability, the proposed approach also appears to have a reasonable chance of success. It approximately parallels the more conventional ASME Code approach to strength design of steel components, with the only major deviations explainable by basic differences in the nature of the materials. A major point here, which may require further documentation, is the use of stress Iimits based on "mean strength," rather than on a "minimum design strength," to which the material is procured. The need for such an approach is, of course, explainable in terms of the larger variability in graphite strength as compared to steel behavior, but this explanation, in my opinion, will likely play an important role in any licensing documentation for the proposed approach. Included in such documentation should be a discussion of process controls necessary to assure that the strength distributions used in the PRA are representative of the actual production material.

For metal components, each heat of production material is certified to meet minimum strength requirements through testing, and the test reports become a permanent part of a material's pedigree. Also, the strength of a heat is uniform enough, and sufficient safety factors are incorporated, such that there is a high confidence that the "minimum strength" will not be exceeded anywhere in the component. A similar, statistically based, assurance of minimum strength distribution may be required for production graphite in order to achieve NRC acceptance of the proposed approach.

On the positive side, the depth to which $G A$ is going in development of the proposed criteria is more analogous to that typically used for critical structural components in LWRs (such as the pressure vessel, piping, and core supports) than to the generally less structurally critical fuel elements. Stress criteria for LWR fuel elements are designer specific, and not covered by the ASME Code. Moreover, it appears from 
the discussion of failure modes and consequences, that failure of an HTGR fuel block ligament (or several ligaments) is less consequential than breech of cladding in a LWR fuel rod, which is an accepted occurrence in LWRs, at a frequency of about $10^{-4}$ per reactor year. This point could be emphasized in licensing documentation for the proposed approach.

2. Graphite Technology Development Plan (Ref. 4)

My primary comment regarding the graphite technology program is concerned with the apparent lack of emphasis on addressing the volume effect concern noted above. It appears, from my review of the graphite criteria over the past several months, that a definitive series of tests using representative core graphite material, and specimen volumes ranging several orders of magnitude upwards from the $1 / 4$ to $1 / 2$ in. diameter tensile specimens run to date, is a high priority need of the program. A test program along the lines of that presented in Ref. 8 is recommended, with specimens carefully designed to include some stress gradient effects as well as specimen volume effects. While it may be intended to include some testing of this type under task 5.2.1 (mechanical properties), the task description is not detailed enough to provide a clear understanding of what testing is planned, nor does this task appear to have the priority and emphasis which I believe it warrants.

Beyond this, I find the technology program to be quite thorough and comprehensive, with the proposed testing focused, for the most part, on specific design needs. Some attention is paid to prioritization of tasks in Figs. 5.1 and 5.2 of the plan, although this is not discussed in the text, and it is not clear how the priorities would be put to use, if as expected, less than the full funding is made available. I would suggest a more rigorous treatment of priorities, with some planning for what testing would be performed if, say only one-half or one-quarter of the requested funding were available. For example, it would seem that the proposed fatigue strength testing could be dropped with little or no impact on the end results, and some of the other physical properties testing may prove unimportant based on parametric studies in the PRA. Potential cost savings may also be achieved through reduction in scope of the irradiation testing (which makes up almost half of the total program cost) if better use were made of the Fort St. Vrain operating experience. Many of the uncertainties and physical effects being tested for are present in the Fort St. Vrain core, and the apparently successful operation of these fuel elements may provide validation of the proposed PRA approach, in lieu of some aspects of the proposed testing program. It is not clear to me that a technology program of the full magnitude and cost of that proposed is 
warranted in view of the relative lack of problems with the Fort St. Vrain fuel elements, and the apparently small consequences of fuel block damage in the MHTGR.

\subsubsection{Comments by $\mathbf{w}$. Tucker}

1. Core Graphite Conceptual Design Criteria (Ref. 5)

I have these comments referring to specific pages of the draft of the report:

a. On page 13, the term "log" needs definition. Also, the value of the Weibull modulus should be stated.

b. On page 14, the term "strength" needs definition.

c. On page 28 , a statement should be added that the mathematical deviation of the failure probability assumes the load $L$ and the strength $S$ to be independent.

d. On page 29, the term "median probability" needs definition. Also, it should be explained how the equation for failure probability relates to the deviation on the preceding page and to subsections 4.5 and 4.6 .

e. On page 30 , explain the distinction between "variation" and "uncertainty."

f. On page 33, the failure model needs better explanation, especially the claim that the model is conservative.

8. On page 35, the discussion in the last two paragraphs reads like a mixing of inherent variability and uncertainty.

h. On page 36, the expression "mean probability" needs definition.

Also, in Sections 4.4, 4.5, and 4.6 there appears to be a confusion of inherent variability; randomness, etc. and subjective uncertainty. This must be corrected and the methodology should reflect a correct application of Bayesian methods. The overall probabilistic concept is sound. However, there may be a better way to implement the procedures than by employing "classical" design limits, for example, use probabilistic methods throughout. Also, great care must be taken in the bounding methods. Again use probability methods directly, since the bounds may not be conservative. 
2. Design Criteria for HTGR Fuel Elements and Other Replaceable Graphite Components (Ref.6)

These comments refer to specific pages of the report.

a. On page 4-3, the contention that weibull theory overstates the volume effects is not supported by the Yahr data.

b. On page 4-4, towards the bottom of the page it is stated that "Failure stresses for intentionally defected samples were found to agree with fracture mechanics predictions." However, Weibull-Batdorf would also agree!

c. On page 6-3, the comparison at the bottom of the page between the GA and the Great Lakes Carbon Company (GLCC) distributions has not properly accounted for the significant differences in the two data sets. Thus, instead of attributing the lack of correlation to incorrect Weibull size effects, the author should explore why the two distributions differ so much.

d. On page 6-5, the favorable statements about the RoseTucker model are challenged, because Rose-Tucker gives a poor fit!

Additionally with respect to the GA and GLCC tensile data, I have the following comments:

a. There is more than just a size effect confounding the results.

b. For any reasonable size effect model, the GA tensile data indicate weakness at larger volumes.

c. A fitted Weibull distribution to the GLCC data differs greatly from that for the GA data. The GLCC data are reasonably fit by

$P(S \leqq \sigma)=1-e^{-0.5968}\left(\frac{\sigma}{1949.15}\right)^{3-1 / 3}-0.5968\left(\frac{\sigma}{2467.56}\right)^{25.46}$

d. The strength of the GLCC tensiles, $\sigma_{0}=1949$, is about twice that of the GA tensiles, $\sigma_{0}=1065$.

e. The Rose-Tucker model fitted to date gives a very poor fit to the GA data. 
At this point I see no reason, as shown by the data, to prefer the Rose-Tucker model over a Weibull model. The recommendation to investigate a range of size specimens is very sound and should be carried out. In so doing, care should be taken to make the results as representative as possible, for example, take a range of size specimens from adjacent material in the logs, measure important material properties, etc. Also, analyze the data set as a whole, that is, do not fit individual distributions at each size but analyze the data as a complete set.

\section{RESOLUTION OF REVIEW COMMENTS}

A systematic point by point resolution of the comments in section 3 requires more time and will have to be deferred to FY-87. A preliminary evaluation has been performed by $G A$ with these results:-

1. The area in greatest need of improvement and clarification is clearly the statistical treatment of the uncertainties. This was pointed out in the panel consensus and strongly emphasized in the individual comments by Cornell, Flemming, and Tucker. One problem in this respect is the terminology; for example the term "uncertainty is used in several different meanings, neither of which is defined. Another problem is an overly simplified description of the PRA model in the criteria report (Ref. 5). These problems will be corrected in the next issue of Ref. 5 scheduled in FY-87. The panel suggestion that GA prepare a listing of the sources of uncertainties and a discussion of how each is treated is being considered in the planning of the FY-87 work.

2. The importance of the volume effect was identified by the panel and also separately by several of the reviewers. In response to these comments, the next issue of the Graphite Technology Development Plan (Ref. 4), scheduled for FY-87, will be strengthened on this point. Also, some volume effect. testing is proposed by ORNL for FY-87.

3. The panel consensus and also the individual comments by Gyekenyesi and Riccardella questioned GA's approach to graphite fatigue. GA agrees with the criticism and intends to re-examine the needs for fatigue testing and revise the technology plan accordingly.

4. Two panel members, Flemming and Gyekenyesi questioned the wisdom of converting the failure probabilities into conventional stress to strength limits. Their suggestion is to express the design criteria in terms of limits on the acceptable failure probabilities for each components. In GA's op inion, this suggestion is not practical since the approach selected for calculating the failure probabilites uses the variabilities both in the strength and in the applied stress. 
If the fallure probabilities had been calculated from the variability in strength alone, as appears to be common in ceramics design, the suggestion would have been practical, because the designer could then perform a weibull integral as a relatively simple extension of the stress analysis. However, to also include the variability in the applied stress is too difficult and too complex to be part of the routine design process. Another reason for expressing the criteria as stress to strength limits is that this form is more amenable to structural engineering judgment.

5. The panel consensus and also Cornell's comments identified a need to examine the spatial correlation of the more important material properties (for example, if the creep coefficient is $10 \%$ above the mean value at some point in the graphite block, is it also going to be $10 \%$ above the mean value at all other points in the same block?). If these properties are random, either partly or fully, rather than correlated, this characteristic can be converted into higher stress limits. GA agrees with the comment. and intends to address this subject in the next revision of the Graphite Technology Development Plan.

\section{REFERENCES}

1. Jones, Graham, "Minutes of the Peer Review Meeting on Graphite Design Criteria," GCRA letter GCRA/DIST (0153), January 14, 1986 .

2. Everline, C. J., and G. J. Cadwallader, "Preliminary Graphite Design Criteria for the $4 \times 250$ MW( $t$ ) HTGR," GA Doc. No. 908006, July 26, 1985.

3. Hosegood, S. A., "Draft Minutes of the Second Peer Review Panel Meeting on Graphite Design Criteria," GCRA letter GCRA/DIST (0173).

4. Gorholt, W., and R. Sullivan, "Graphite Technology Development Plan," GA Document No. PC-000213, July 17, 1986.

5. Alloway, R., and W. Gorholt, "Core Graphite Conceptual Design Criteria," GA Document No. 908950, August 29, 1986.

6. "Design Criteria for HTGR Fuel Elements and Other Replaceable Graphite Components," Report No. SIR-86-016, July 23, 1986, prepared by Structural Integrity Associates.

7. Brown, S. J., "Draft Minutes of the Third Peer Review Panel Meeting on Graphite Design Criteria, September 4/5, 1986," GCRA letter GCRA/DIST (0280), September 12, 1986. 
8. Tucker, M. O., A. P. G. Rose, and T. D. Burchell, "The Fracture of Polygranular Graphites, "Central Electric Generating Board, Berkeley Nuclear Laboratories, March 1986. 
$909028 / 0$

APPENDIX A

MINUTES FROM NOVEMBER MEETING

Page A-1 


\section{DRAFT}

\section{MINUTES OF THE PEER REVIEW MEETING ON GRAPHITE DESIGN CRITERIA}

November 19 and 20 at GA Technologies

The meeting was opened with a presentation by Ray Ng on behalf of DOE which gave the key objectives of the HTGR Program and the key objectives of the review (See Attachment \#1). The latter were:

- To assess whether the approach proposed is sound in principle

- To assess whether the approach will be acceptable to NRC staff for design and licensing of HTGR Graphite Core Components

- To assess whether the methodology and statistical data base can be developed within the anticipated program schedule and budget

Further objectives for the next phase, if the conclusions to the above are positive, were:

- To assure that the specific methodology to implement the approved approach is being correctly developed

- To assure that the necessary statistical data base is provided by the planned technology program

The review panel was composed of the following members:

$$
\begin{aligned}
& \text { Mr. Karl N. Fleming (Chairman) } \\
& \text { Dr. C. Allin Cornell } \\
& \text { Dr. John P. Gyekenyesi } \\
& \text { Dr. Robert A. Meyer } \\
& \text { Dr. Peter C. Riccardella } \\
& \text { Dr. William Tucker }
\end{aligned}
$$

There followed a series of presentations by GA Technologies and ORNL staff according to the agenda appended to these minutes, explaining the HTGR design, the materials involved and the criteria currently proposed. Attachments 2 thru 16 are the materials that were handed out during the course of the presentation. A list of attendees is also appended.

Additional clarifications provided during the course of the meeting were as follows:

- The plant design life is 40 years at $80 \%$ capacity factor

- The reactor internals as a whole are designed to last the life of the plant but are replaceable with difficulty 
- The review should be limited to those components which are replaced during refueling, that is, the fuel elements on a three year cycle and the replaceable hexagonal reflector elements on a nine year cycle

- The remaining graphite components are being designed to the joint ACI/ASME Code section III, Division 2, Subsection CE

- The major loadings on the fuel blocks were strain controlied stresses due to the thermal and irradiation environment. Seismic loads were the major primary loads. The seismic loads for an SSE represented 15-20\% of the total load in the case of the large HTGR. Thermal stresses were previously thought to be small but this was later found to be incorrect

- There is very little structural interaction between the fuel elements except in a seismic event (assuming nothing is dropped during refueling)

- The only direct safety consequences of graphite problems that were identified in the meeting were possible control rod channel blockage. Coolant channel blockage is also of concern although the safety consequences of local coolant channel blockage are minimal

- The fuel element dowels are designed so as not to transfer loads except in a seismic event

- No stress calculations had yet been performed on the 350 MWt design fuel elements, but stress/strength ratios were expected to be in the range of 0.4 to 0.5 when using a deterministic method

- Use of the integrated approach methodology had shown that investment risk not safety may well be the Iimiting factor on the design. This is based on the perceived likelihood of a mandated shutdown following the observation of a fuel element cracking above the limits allowable by the design criteria (Preferably none)

- The proposed maximum stress criteria have been under development at GAT and ORNL for about three years at the one man year level/per year

- The ability quoted by ORNI to correlate some graphite parameters with density has not been used by GAT in the design process. It is assumed that density variation in the core is a minimum

- Irradiation creep capsules cost about $\$ 500 \mathrm{~K}$ per capsule

- Funding levels to support the overall HTGR program at DOE are expected to be in the $\$ 30 \mathrm{M}-\$ 50 \mathrm{M}$ per year range for the foreseeable future 
The panel briefly reviewed the criteria with respect to the three main objectives, the conclusions are given below together with other findings which may be useful to the design team.

The panel plans to meet with the design team early in February 1986 to discuss these findings and to support the preparation of a graphite technology plan.

\section{Is the Approach Proposed sound in Principle?}

The panel found the PRA based approach to be technically and conceptually sound and to be preferable to a purely deterministic approach. In coming to this conclusion, the panel noted that some of the "boxes" on the logic flow diagrams had not been fully thought out at this stage. The panel is confident that a systematic approach with the details of the PRA structural engineering, material and testing interfaces can be worked out and believed that this is critical to the success of this effort.

To help achieve this, the recommendation was made that a pilot study would quickly bring to light any undiscovered problems in applying the methodology and to also allow the key variables to be identified early in the process. Further, once the main study has been initiated, every attempt should be made early to determine the sensitivity of results to all the variables, knowing that some variables may be able to be discarded early on. That is, do not concentrate on the items that are easy or interesting to work on but try to determine what will drive the end result. For instance, is a low probability, high level earthquake loading, going to dominate the reliability calculations or is it the normal operating stress level in the fuel element, or the normal operating stress in the replaceable reflector that has no crack stopping coolant holes? What is the risk role of horizontal cracks for which there is no crack stopper?

Further, if many graphite properties can be tied to density then it may be possible to reduce the total number of variables used. However, more data needs to be obtained on H45I grade graphite in order to properly validate the correlation between physical properties and densities

The above approach will maximize the cost effectiveness of the task. In addition to the possibility that it may be required by the NRC, it is a realistic and robust integrator of complex phenomenon for which there is little purely experience based precedent

\section{Will the Approach be Acceptable to NRC?}

The panel found to the extent they were able to assess, that the approach should be acceptable to the NRC providing it is thoughtfully "packaged". It is recommended that the stress criteria be stated as a deterministic stress limit or limits 
which had been obtained using probabilistic methods. This would be consistent with the "stress to strength" ratio proposed by GAT, and the multiple stress criteria currently in use for ASME code for metallic design. (See Attachment 17)

Although a PRA supporting the above is not in place, the basic concept of permitting higher stress to strength ratios for lower probability events is incorporated in keeping with a general PRA based approach.

A major point that should be emphasized in presenting the final criteria to the NRC is the limited connection between graphite behavior and plant safety. The panel noted that during the entire meeting, direct connections or scenarios involving graphite problems leading to fission product release were never established except for that which may be implied by control rod channel blockage.

The approach to be presented to the NRC should be clearly shown to be an integral part of the overall plant design by an integrated approach to probabilistic risk analysis and not an isolated task used solely to establish a lower design limit for replaceable graphite components.

3. Can the Methodology and Data Base be Developed Within the Anticipated Program Budget and Schedule?

The panel considered that based on the need for final criteria by 1989, there was every expectation of success and that the cost would be in the range of $\$ 10 \mathrm{M}$ to $\$ 30 \mathrm{M}$. However, more confirmation will be required to better establish the cost.

In particular, the graphite strength characterization program was expected to require some 100 to 300 specimens for a given temperature and exposure. However, the precursor to this program was a study based on known background of disparate flow size and distribution, on existing Weibull correlations, and on the component configurations for the fuel element and the replaceable reflector to determine what size or sizes and configurations of specimens would be required. suggestions were made that this might result in at least two sizes of specimens and in bend tests not tensile tests where possible. This study was thought to be a few months effort. The following characterization tests should also be done in a manner that would allow production control tests for the production grade graphite to be specified so as to ensure that the quality of the final product fell within the scatter band of the material used in the test program in all aspects.

The panel saw the need for a small amount of testing on the full scale components, proof testing being the most reliable form of testing.

The above conclusions relate to all testing aspects save the expensive irradiation creep tests. The importance of this property to the successful behavior of the components was emphasized. The panel was not given any significant data on the past or planned irradiation creep testing but suggested that if the variability of the major properties of graphite 
can be related to density and/or disparate flaw size and distribution then a thorough characterization of new graphite should be used in an attempt to minimize the number of irradiations planned to investigate the rate of creep as a function of temperature and its variability.

The timescale and budget for the development of the methodology was not considered to be a problem. The need to have the structural analysis team fully understand probabilistic methodology is fundamental to achieving the schedule and cost goals and definite improvement was required in this area. As it stands, the two parts are not soundly tied together and this is a must for the probabilistic approach.

\section{OTHER FINDINGS}

- It may be difficult using traditional engineering concepts to arrive at one single stress/strength ratio value as a criterion given the three major loading cases:

- strain induced stress with crack stoppers (coolant channels)

- strain induced stress without crack stoppers

- Mechanical load stress

While a single ratio may suffice for the PRA computations, consideration should be given to specifying multiple ratio values to designers to cover multiple failure modes.

- The criteria may well be specific to a design configuration in the case of the first of the above cases, a component with stress with crack stoppers

- The criteria will be specific to one grade of graphite as supplied for characterization

- Using PRA has two problems that are not found in deterministic methods and which will result in frustration if the scoping studies are not well done or not comprehensive enough. That is, the outcome may be very sensitive to changes in assigned probabilities. Also, changes in the assessment of low probability and high consequence events may possibly drastically change the design conclusions late in the process

- The early demonstration of the low probability of multiple failures in most events should be targeted. Extreme care should be given to models and assumptions in working from single block and multiple block analyses

- The use of brute force Monte Carlo simulations as proposed should be replaced by more analytical techniques, (eg., advanced first order analysis, 
response surface methods with formal experimental design); the panel would offer its help in supplying references and contacts to assist in this. This should result in considerable time and cost savings over the proposed approach

- Perhaps the quality control program of the graphite manufacturing process should be considered in addition to the testing program as a means of controlling the risks of stress/strength criteria exceedance

- The proposed approach entails the integration of probabilistic methods with some engineering methods that have been historically viewed by many as deterministic. It is very important that the detailed development of this new approach to stress criteria take full advantage of recent advances in such bridge technologies as stochastic finite element analyses and probabilistic structural and mechanical design

- There was a characteristic PRA terminology problem in some of the presentations and review documents that needs to be cleared up. The problem stems from the use of the concept of probability to describe random processes on the one hand and uncertainty on the other 


\section{APPENDIX B}

MINUTES FROM FEBRUARY MEETING

Page B-1 
DRAFT

\section{MINUTES OF THE SECOND PEER REVIEW MEETING ON \\ GRAPHITE DESIGN CRITERIA \\ February 4th 1986 at GA Technologies}

\section{In Attendance}

Panel Members:

Karl N. Fleming (Chairman)

c. Allin Cornell

John P. Gyekenyesi

Robert A. Meyer

Peter C. Riccardella

William Tucker

U. S. DOE Representative:

Art Mehner

GA Technologies staff:

Henry Jones

willie Gorholt

Tom Dunn (part time)

Rick Alloway (part time)

ORNL staff:

Walt Eatherly

Terry Yahr

GCRA Representative

Sam Hosegood (Secretary)

Plckard Lowe Garrick, Inc. CAC, Inc./stanford U.

NASA/LERC

Aerospace Corp.

structural Integrity Assoc. GE/CRD

\section{Agenda}

The agenda for the meeting consisted of a point-by-point review of the conclusions recorded in the (draft) minutes of the first meeting (of November 19-20 1985) with detailed explanation and discussion of the points of concern by Panel members and responses from the ORNL and GA staff.

\section{Graphite Technology Development Plan}

It was pointed out that the proposals presented at the first Review panel meeting and now being discussed were preliminary and tentative. The DOE Graphite Technology Development Plan was currently being prepared by GA and ORNI staff; this would consist of two parts:

- A review of the design and the requirements arising from it - prepared by GA Technologies

- A development program in response to these requirements - parpared by ORNI

When ready, the draft plan would have to be approved by the $D O E$ and a further meeting of the panel to review the plan 
would be convened as soon as possible after this. Hopefully this could be held in May 1986.

\section{Review of Conclusions from the First Panel Meeting}

1. Is the Approach sound in Principle?

Development of Deston Criteria

The consensus view was that not only was the PRA approach sound in principle, it was the only sound approach for designing highly stressed components in a material such as graphite with a statistical distribution of strengths. However some concern was expressed over the steps needed to derive deterministic design criteria from the PRA analysis as a considerable amount of work remained to be done in this area. Three stages were identified as:

- Determining design requirements (fluences, temperatures, fluence and temperature gradients, external loads, etc.)

- Development of the material data base

- Use of the data and design conditions to model cracking and crack progression in service

Need to distinguish between uncertainties and statisticaliy variable properties

The Panel expressed concern over the dangers of confusing parameter or model uncertainty margins with statistically distributed property variations in carrying out this work. Methodology as well as terminology could be at stake here. Dr. Tucker had marked up a copy of GA document No. 908006, entitled "Preliminary Graphite Design Criteria for the $4 \times 250 \mathrm{MW}(t)$ SBSV HTGR", expressing his concern that results would be difficult or impossible to interpret if the methodology failed to keep subjective probabilities (1.e. those expressing confidence levels) separate from probabilities defining systematic variability (e.g. Weibull distribution of graphite strength). He undertook to send copies of his marked up pages to those in attendance. There were well defined rules for treating problems involving two different kinds of probabilities. Elther they would have to be treated separately until the end of the analysis or a Bayesian approach would have to be adopted all the way through. There was general agreement that a Bayesian approach would be necessary for putting the graphite fallure risk analysis into the plant PRA.

Definition of failure

There was also considerable discussion of the definition of "failure" as applied to the graphite core components, since the entire approach is based on the argument that limited cracking is acceptable. GA put forward 5 failure criteria based on their effects on Goals 2 (Maintain plant 
protection) and 3 (Maintain control of radionuclide release) of the Integrated Design Approach. These were cracking leading to:

- Unacceptable fission product release

- Excessive flow interruption

- Interference with the entry of control absorbers

- Interference with handling for refueling

- Perceived faults

In amplification it was pointed out that blockage of a single coolant passage would not lead to excessive fission product release and could be allowed. Perceived faults were any which, while arguably not serlous, might be regarded with concern by the NRC, resulting in delays before the reactor could be re-started. Any crack pattern extending all the way from the outside to the central hole would be regarded as a fallure and so would any crack pattern resulting in a piece of the block becoming detached from the remainder. The question of a "beyond design basis" seismic event was raised but $G A$ reported that this had been examined and the probability of reducing the core to rubble had been found to be acceptably low. It was also remarked that, for the 350 MW( $t)$ HTGR design under consideration, the safety consequences of even this extreme eventuality would be limited. Overall the envelope of event conseguences and probabilities fell well within the NRC's safety requirements on a probabilistic risk basis; the envelope for investment risk presented much more difficult requirements.

P1lot study

The Panel recommendation that there should be an early pilot study was raised and GA confirmed that sensitivity studies were being done and fed back to ORNL to focus attention on those properties which have a large influence on the stresses.

Correlation of graphite properties with density

There was some hope that the lield for investigation could be limited by the correlation exhibited by a number of graphite properties with density. Bulk density is variable within the blocks and also varies with irradiation. During irradiation shrinkage, bulk material is densified by about 15 s and, as that happens, its variability decreases. For a particular graphite (where crystallite orientation is effectively fixed by the manufacturing process), the UTS $\left(\sigma_{f}\right)$, Youngs modulus (E) 
and sonic attenuation $(\alpha)$ are correlated in unirradiated material by the following relationships:

$$
\begin{aligned}
\sigma_{f} \propto \sqrt{\frac{E}{\alpha}} & =\sigma_{0} \cdot e^{-s_{1} \delta_{p}} \\
\sigma_{f} & =E_{0} \cdot e^{-s_{2} \delta_{p}} \\
\alpha & =\alpha_{0} \cdot e^{-s_{3} \delta_{p}} \\
\therefore S_{1} & =\frac{s_{2}-s_{3}}{2}
\end{aligned}
$$

Where: $\delta \rho$ denotes changes from the mean density, suffix 0 denotes mean properties and $s_{1} s_{2}$ and $s_{3}$ are constants. It is not yet ${ }^{1}$ known whether these relationships will hold good for irradiated material and a variance analysis is needed to establish the correlations. Somewhere in the order of 100 data points with enough moment about the mean will be needed to establish the correlations for data sets with a cov of about $20 \%$.

\section{Will the Approach be Acceptable to NRC?}

Importance of presentation

Several panel members expressed doubts about the readiness of the NRC staff to accept a PRA approach as something other than an admission of failure to comply with an acceptable deterministic limit. Tradition and background might predispose them to think in "black and white" terms. The panel confirmed its view that appropriate "packaging" would be important, showing how deterministic design criteria were derived from the PRA approach and could be related back to acceptable service behaviour. It would be important to emphasize the remoteness of connections between graphite block "failure" and actual safety problems. GA pointed out that the ACRS have welcomed the adoption of a PRA approach and that the NRC Commissioners themselves appeared to be receptive to the idea that a different approach would be needed for the HTGR than had been adopted for the LWRs.

Full scale proof tests

The idea of using an "overloaded" block or blocks (i.e. with extra high thermal gradients etc.) in the first demonstration plant was discussed briefly but the opinion was expressed that this would be too risky. This led to a suggestion that Fort st. Vrain blocks, a number of which could be predicted to crack by the present design methods, could be used as proof test specimens as they were much more highly stressed than any in the 350 Mwt HTGR design. GA did not consider this would be very convincing as the original Fort st. Vrain safety submission had been made on the assumption that cracking was not expected. It was also pointed out that removal and repackaging (for disposal) of the spent fuel sticks would be expensive. 
The idea of test loading production blocks before acceptance, so as to eliminate the weakest ones was dismissed on the grounds that the test could not duplicate service conditions and would only weaken the blocks.

The meeting was reminded that graphite components have proved to be surprisingly robust in reactor service and ORNL confirmed that thermal stress experiments on AGOT graphite had demonstrated the arrest of cracks where they ran into regions of compressive stress. 1451 could be expected to behave like AGOT in this respect. GA confirmed that full-scale multi-hole fuel blocks had been repeatedly impacted against each other, to simulate the effects of an earthquake, with no apparent damage. H451 graphite was said to exhibit considerable "toughness" with strain to fallure in tension 2 or 3 times the elastic strain.

3. Can the Methodology and Data Base be Developed within the Anticipated Program Budget and Schedule?

Cost and number of tests

The discussion on this point took up a major portion of the meeting. It was felt the forecasts of cost and numbers of irradiation specimens, as recorded in the draft minutes of the first meeting, might have to be revised after further studies by ORNI and the issue of the draft Graphite Development Plan.

Irradiation creep

Concern was expressed over the sensitivity of conclusions to the results of irradiation creep tests since significant numbers of test capsules might be required to obtain statistics. GA and ORNL were currently examining strategies for limiting requirements in this area.

Governing parameters

Walt Eatherly described the parameters governing radiation creep in graphite. There was a pseudo-elastic primary creep:

$$
\epsilon_{0}=A \sigma\left(1-e^{-\lambda \Phi}\right)
$$

Where: A is well known (proportional to Youngs modulus) $\sigma=$ stress $\Phi$ is the fast neutron fluence $\phi t$ (Energy>0.05MeV) and $\lambda$ is difficult to determine experimentally but $\lambda^{\prime}$ is of the order of 1-2 weeks.

The primary creep is quickly exhausted and is followed by an irreversible steady state secondary creep whose rate is linearly dependent on flux $\phi$ and stress $\sigma$,

$$
\text { 1.e. } \dot{\epsilon}=k \phi \sigma \widetilde{B} \Longrightarrow \text { (constant Volume) }
$$


Here $k$ is very temperature dependent, falling sharply to a minimum at $475-500^{\circ} \mathrm{C}$ and rising at higher temperatures. There are indications that $k$ is related to thermal expansion but this has not yet been established. The effect of reducing load during irradiation would be to recover a proportion of the (elastic) primary creep and to reduce the rate of the subsequent secondary creep. Irradiation creep in graphite is a crystallite distortion phenomenon which involves breaking and reforming covalent grain boundary bonds. We are roughly $2000^{\circ} \mathrm{C}$ away from thermal creep in graphite.

\section{Experimental determination}

Irradiation creep is measured experimentally by capsule tests containing both stressed and unstressed specimens; dimensions of both change under irradiation and the difference is attributed to creep. There is very little difference between tensile and compressive creep. Both U.S. and German experiments are done at constant load but some old U.K. experiments were done at constant displacement. ORR capsules contained 4 columns of 14 samples each; two were stressed and two unstressed. With the shut-down of the ORR, experiments will have to be done in HIFER where the capsules only accommodate three columns of 14 samples. Furthermore, they will have to be rotated regularly to even out exposures as they will be situated in sharp flux and temperature gradients; this is obviously far from ideal.

\section{International Co-operation}

The possibility of enlarging the data base by exchanges of information with the Germans and/or the British was raised and the response was that it has become difficult to get access to German data, apparently due to commercial policy. Germany had earlier been an important source of information as they had been working on a dozen different kinds of graphite, whereas the U.S. work was all on H451. However the Germans had currently cut off all information except on H45I. On the other hand ORNL do have access to British data on Gilso graphite which is extremely helpful. They were looking for correlations because it would be impossible to do statistical numbers of experiments.

Variability of properties

The Weibull exponent $m$ has only been recognized in the last 4 or 5 years as a well characterized property of graphite because of the effect of density. Once the density effect is factored out, graphite strength is well correlated by $m$. Fast fracture probability can be predicted by the weibull correlation but, if we leave the component under load, subcritical crack growth will reduce its strength and reliabllity so this time dependent damage will leave a Weibull form of distribution but with a different strength $\left(\sigma_{f}\right)$ and a different scatter (m). ORNI 
have started looking at the effects of irradiation on $\mathrm{K}_{\mathrm{IC}}$ and flaw size. Flaw sizes are measured by sonic scatter as well as by measurement of tensile strength and use of fracture mechanics. Surprisingly $K_{\text {re }}$ remains constant with irradiation up to high doses ( $G_{\text {Ic }}$ had been expected to remain constant but not $K_{I_{k}}$ ). The apparent flaw size falls to a minimum and then increases and here the reduction in llaw slze seems to be assoclated with material densification during the shrinkage stage with subsequent increase as the materlal goes into expansion. Fortunately the 350 MWt HTGR design does not require the material to go beyond the minfmum of the curve as some of the earlier designs. (particularly the pebble bed design) had.

Summarizing on how well the statistical variability of the properties was known, Walt Eatherly sald they could be separated into two groups, viz:

10\% standard Deviation

coefft. of thermal expansion

Young's modulus

Polsson's ratio

Unloaded Irradiation

dimensional change $\geq 20 t$ standard Deviation

Thermal conductivity

Ultimate strength

secondary creep coefft.

Disparate elaws

A simple view would suggest that, while background flaws are the dominant influence on which the properties determining stress build-up depend, the failure probability at a given stress level may be almost entirely dependent on disparate flaws. One of the aims of the program is to verify this hypothes1s. Disparate flaws are probably little egg-shaped pitch volds; a typical ligament between the fuel and coolant holes in a core block would contain about 9 disparate flaws. The 4451 Weibull in value is about 7 and, while this could be ralsed as high as 20 , that would double the cost. The desirablitity of a large enough experiment to verify the significance of the disparate flaws was agreed.

GA Presentation of Desion Features and Reculirements

Henry Jones explained that fuel elements would have a core residence time of about 3 years with half (alternate columns) being replaced at 18 month intervals. Fuel element columns would have a normalized power history starting at the nominal value, rising to a peak of about 1.4 times nominal power some 9-12 months after loading before falling to re-cross the nominal power line at 18 months and then continuing to fall to about 0.6 times nominal power by the end of the 3 year fuel iffetime. Adjacent columns would have been replaced (off load) half way through this period. 
The fissile loading in the fuel columns would be graded to flatten the axial fuel temperature distribution with the top 5 elements highest loaded, the next 3 intermediate and the bottom 2 having the lowest loading. The annular fueled region of the core would be 3 columns wide so, depending on which columns had been refueled most recently, neutron flux, power and temperature tilts could be large and either radially inwards or outwards. partly inserted control rods could further complicate these tilts.

The resultant temperature and fluence variations cause differential thermal and irradiation shrinkage stresses which, in general, are greater in the horizontal than the vertical direction so current stress analyses are 2-D, looking at the horizontal stresses in the webs. Vertical stresses and the probability of horizontal crack growth will also have to be looked at eventually. Irradiation creep relieves the bulid-up of operational stresses which therefore peak soon after the power peak has passed and thereafter diminish as the fuel element power falls. However the portion of the thermal stress which has been relieved by creep must reappear (with reversed sign) as soon as the thermal gradients responsible for the original stress are removed. This reversed thermal shut-down stress thus continues to build up throughout the fuel element lifetime. However, in the present 350 MWt HTGR design, at the end of life, it will only have reached a value roughly comparable to the peak operational stress. Values relative to the Fort st. Vrain peak operational graphite stress were given as:

Fort st. Vrain 350 MWt HTGR
Peak Operating stress Shutdown stress
1.0
$\sim 0.5$
1.3
$\sim 0.5$

The analysis method scans the core blocks to identify the most highly stressed ones which are then subjected to detailed 2-D finite element analysis to determine the web stresses. If cracking behaviour is determined by the presence of disparate flaws it is important to know the probability of a disparate flaw being present at a high stress point. The analysis will not just look at peak stress regions but also at regions where uncertainties may be higher although predicted stresses are lower. Here Covs may be 30-50\% at end of life. Finally, where high cracking probabilities are indicated, crack progression studies will be undertaken to determine whether the end result is likely to be an acceptable crack pattern or "failure".

The thermal and irradiation stresses are the result of "self-stressing" in the blocks and must tend to be relieved by cracking which reduces the stored strain energy. A seismic event on the other hand introduces 
ACTION

GA TECHNOLOGIES

external loading but the resultant stresses only add about 208 to the total. Finally the results of the PRA analysis have to be used to define design criteria which will result in an acceptably low probability of "failures".

Dr. Gyekenyesi asked to be provided with papers on the core structural analysis, since he felt there were some aspects of the total approach for whlch he needs to look at the probabilistic aspects. GA agreed to supply him with the appropriate papers.

\section{other findings}

- The designers agreed with the panel that a single stress/strength ratio may not be a sufficient design criterion.

- It was agreed that the criteria would be specific to the design for which they had been derived.

- It was further agreed that the criteria would be specific to one grade of graphite, as used for characterization. In this connection it was noted that a quality assurance program would be needed to ensure that future batches of graphite retained the same characteristics.

- It was suggested that the sensitivity of results to changes in the probabilities assigned for low frequency, high risk events could bring in site specific problems for seismic events. However GA stated that they had studied an envelope of sites for soll conditions, etc. and were satisfied that the design would be suitable for the targeted 808 of U.S. sites.

- Monte-carlo methods may not be the most efficient way, especially since the discussions had uncovered a possible need for 2-tiered Monte-Carlo to combine uncertainties with statistical distributions and the finite element code for stress analysis would be a monstrous sub-routine. Nevertheless it may be more economic to use computer time on Monte-Carlo methods than to use man hours to develop more sophisticated programs.

- The use of acoustic examination to screen out blocks with large disparate flaws was discussed but it was realized that this could not rule out the generation of new disparates during subsequent machining, transport and handling. Fast off-load refueling of half the core could itself introduce new surface flaws. 


\section{Next meeting}

The next meeting will consider the:

- Graphite Technology Plan

- Uncertainty study

- PRA Methodology

These papers will be issued in time for study ahead of the meeting but the Technology plan cannot be distributed until it has been approved by the DOE. This was thought to make April too soon and it was decided that an attempt would be made to select a date in May as soon as the plan has been drafted and submitted to the DOE.

S. B. Hosegood

Feb. 7th, 1986 